\title{
Prevalence and Correlates of Suicidal Thoughts and Behaviors among North Korean Defectors
}

\author{
Ji Hyun An¹, Kyoung Eun Lee1, Hyo Chul Lee', Hae Soo Kim¹, Jin Yong Jun², \\ Hye In Chang ${ }^{3}$, Suk Sun Kim ${ }^{4}$, Su Yeon Lee-Tauler ${ }^{5}$, and Jin Pyo Hong ${ }^{1 凶}$ \\ ${ }^{1}$ Department of Psychiatry, Sungkyunkwan University School of Medicine, Samsung Medical Center, Seoul, Republic of Korea \\ 2Department of Psychiatry, Seoul National Hospital, Seoul, Republic of Korea \\ ${ }^{3}$ Department of Psychology, Sungkyunkwan University, Seoul, Republic of Korea \\ ${ }^{4}$ College of Nursing, Ewha Woman's University, Seoul, Republic of Korea \\ ${ }^{5}$ Department of Mental Health, Johns Hopkins University, Baltimore, Maryland, USA
}

Objective Despite the increasing number of North Korean defectors, research on their mental health conditions and suicidal thoughts and behaviors has not been conducted systematically. We examined the prevalence and risk factors of suicidal thoughts and behaviors in North Korean defectors.

Methods This study focused on 300 North Korean defectors recruited from regional resettlement centers in South Korea. In-person interviews based on the North Korean version of the Composite International Diagnostic Interview were conducted to diagnose mental disorders and assess suicidal thoughts and behaviors. Logistic regression analyses were performed to evaluate the association between suicidal thoughts and behaviors and socio-demographic variables, and DSM-IV mental disorders.

Results Lifetime prevalence of suicidal ideation, plans, and attempts were $28.3,13.3$, and $17.3 \%$, respectively. Female sex (OR: 2.0, $95 \%$ CI: 1.0-3.9), presence of health problems in the past year (2.6, 95\% CI: 1.4-4.6), and absence of both South Korean acquaintances (1.9, 95\% CI: 1.0-3.4) and North Korean family (1.7, 95\% CI: 1.0-2.9) were associated with higher odds of suicidal thoughts and behaviors, after adjusting for participant age, sex, and education. Presence of a mental disorder was associated with a significantly increased odd of suicide ideation, plan, and attempt. Of all mental disorder categories, agoraphobia had the strongest association with suicidal ideation (6.5, 95\% CI: 2.0-21.6), plans (7.7, 95\% CI: 2.5-23.2) and attempts (12.0, 95\% CI: 3.5-40.8).

Conclusion Suicidal thoughts and behaviors among North Korean defectors are higher than the general population in South Korea, especially show high rates in transit countries. Further study should focus on the changes in suicidal thoughts and behaviors according to the settlement process and early prevention.

Psychiatry Investig 2018;15(5):445-451

Key Words North Korean defectors, Social connectedness, Suicide, Mental health.

\section{INTRODUCTION}

The number of North Korean defectors has increased rapidly since the late 90s with a total of 1,418 arriving in 2016. As of 2017, it is estimated that there are about 35,000 North Korean defectors in South Korea. ${ }^{1}$ North Korean defectors ex-

\footnotetext{
Received: August 1, 2017 Revised: October 30, 2017

Accepted: November 8, 2017

$\triangle$ Correspondence: Jin Pyo Hong, MD, PhD

Department of Psychiatry, Sungkyunkwan University School of Medicine, Samsung Medical Center, 81 Irwon-ro, Gangnam-gu, Seoul 06351, Republic of Korea

Tel: +82-2-3410-3585, Fax: +82-2-3410-0050, E-mail: suhurhong@gmail.com

(c) This is an Open Access article distributed under the terms of the Creative Commons Attribution Non-Commercial License (http://creativecommons.org/licenses/bync/4.0) which permits unrestricted non-commercial use, distribution, and reproduction in any medium, provided the original work is properly cited.
}

perienced various psychological trauma in the course of their stay in North Korea or in the process of escaping from one or more transit countries. ${ }^{2,3}$ Even after settlement in South Korea, the defectors are known to experience mental health problems due to acculturative stress involving political and cultural differences, identity crises, financial difficulties, and others. ${ }^{4,5}$ As a result, it has been reported North Korean defectors experience psychiatric symptoms such as depression, anxiety, somatization symptoms, and PTSD at a higher rate. ${ }^{2,4,6}$ Nonetheless, there are few studies reporting the overall mental health status of defectors. Existing studies show substantial variability in the prevalence of psychiatric disorder due to lack of standardized diagnostic tools. Despite the fact that the prevalence of suicidal thoughts and behaviors in refugees worldwide is high, ${ }^{7-10}$ studies on the suicidal thoughts and behav- 
iors of North Korean defectors also have been rarely conducted. Although one study showed that longer durations after entrance to South Korea were related to high rates of suicidal ideation, ${ }^{11}$ research on specific risk factors of suicidal thoughts and behaviors toward North Korean defectors has not been conducted.

The aims of this study are to investigate the prevalence of lifetime suicide behaviors including suicidal ideation, plan and attempts in North Korean defectors, and to evaluate psychosocial variables and psychiatric diagnoses related to suicidal thoughts and behaviors.

\section{METHODS}

\section{Data source and collection}

This study was conducted between June 1 and October 31, 2016. Participants were selected from 8 regional resettlement centers (Hana Center) across the country. The target population included all eligible residents aged 18 to 70 years who have arrived in South Korea less than 3 years before assessment. A total of 300 persons participated in this study which was about $10 \%$ of all eligible North Korean defectors.

Psychology, nursing and social work graduate students in mental health-related departments received the WHO-recommended CIDI training and performed face-to-face interview after the training. This study as approved by the Institutional Review Board of Samsung Medical Center (SMC 2015-05-042002). All of the participants were fully informed about the aims and methods of the study before the interview.

\section{Measures}

Assessment of lifetime DSM-IV disorders. This study administered the North Korean version of Composite International Diagnostic Interview 2.1 (NK-CIDI 2.1) to each subject. The CID I (World Health Organization, 1990) is a fully structured diagnostic interview designed to make psychiatric diagnoses using the definition and criteria of the DSM-IV. ${ }^{12}$ The NK-CIDI was developed by Lee et al., ${ }^{13}$ after modifying the Korean-language version of CIDI considering the sociocultural background of North Korea and showed satisfactory reliability and validity among the North Korean defectors. Lifetime DSM-IV disorders included anxiety disorder (generalized anxiety disorder, agoraphobia, panic disorder, social phobia, specific phobia and posttraumatic stress disorder), mood disorders (major depressive disorder, dysthymia and bipolar disorders), nicotine use disorder and alcohol use disorder (alcohol dependence and abuse).

Assessment of lifetime suicidal thoughts and behaviors. NKCIDI module on suicide was used to assess lifetime suicidal thoughts and behaviors; lifetime suicidal ideation with the item "Have you ever seriously thought of dying by suicide?" lifetime suicidal plan with the item "Have you ever made a plan for suicide?" and lifetime suicidal attempts with the item "Have you ever attempted suicide?", recorded as dichotomous (present or absent) variables. Geographic location, timing, frequency and specific suicide tools of suicidal thoughts and behaviors were assessed by participants' self-report. The relationship between each socio-demographic variable and DSMIV disorder and the lifetime suicidal thoughts and behaviors were analyzed.

\section{Data analysis}

Weighting adjustments were made for each participant to approximate the national population distributions of age and sex according to the 2015 Census (Korea National Statistical Office, 2016). ${ }^{14}$ The lifetime prevalence of suicidal thoughts and behaviors including suicidal ideation, plans and attempts were calculated by sex. Socio-demographic characteristics were entered in the statistical analyses as categorical variables. Logistic regression analyses (univariate and multivariate) were performed to evaluate odds ratios of socio-demographic variables and DSM-IV psychiatric disorders with each suicidal thoughts and behaviors after adjusting for age and gender distributions according to the age, sex and educational level. Missing data were excluded from analysis. All statistical analyses were performed with statistical package for the social sciences (SPSS) version 23.0 (IBM Corp., Armonk, NY, USA), with statistical significance cutoff at an alpha level of 0.05 .

\section{RESULTS}

\section{Lifetime prevalence and gender or location differences of suicidal thoughts and behaviors}

Table 1 presents the lifetime prevalence of the suicidal thoughts and behaviors of the participants. Lifetime prevalence of suicide ideation, plans, and attempts among North Korean defectors were $28.3,13.3$, and $17.3 \%$, respectively. $31.3 \%$ of the total participants experienced any suicidal ideation, plan, or attempt in their lifetime, which was significantly higher among females $\left(34.5 \%, \chi^{2}=4.95, \mathrm{p}<0.05\right)$. We also found that suicide ideation, planning, and attempt were developed at highest rate in the third transit country than in North Korea or after transferring to Republic of Korea, 17.7\% (53 of 85), 9.0\% (27 of 40), $11.7 \%$ (35 of 52), respectively (Table 2 ).

\section{Sociodemographic correlates}

Associations between lifetime suicidal thoughts and behaviors and sociodemographic variables were presented in Table 3. Female sex was significantly associated with suicidal ideation $(\mathrm{AOR}=2.0,95 \% \mathrm{CI}=1.0-3.9)$ and any of lifetime suicid- 
Table 1. Lifetime prevalence ${ }^{a}$ of suicidal ideation, plan and attempt among North Korean defectors residing in South Korea

\begin{tabular}{|c|c|c|c|c|c|}
\hline Categories & Male $(\mathrm{N}=65, \%)$ & Female $(\mathrm{N}=235, \%)$ & Total $(\mathrm{N}=300, \%)$ & $\chi^{2}$ & $\mathrm{p}$ \\
\hline Suicidal ideation & $12(18.5)$ & $73(31.1)$ & $85(28.3)$ & 3.98 & 0.046 \\
\hline Suicidal plan & $6(9.2)$ & $34(14.5)$ & $40(13.3)$ & 1.21 & 0.272 \\
\hline Suicide attempt & $8(12.3)$ & $44(18.7)$ & $52(17.3)$ & 1.46 & 0.227 \\
\hline Any suicidal thoughts and behaviors ${ }^{\mathrm{b}}$ & $13(20.0)$ & $81(34.5)$ & $94(31.3)$ & 4.95 & 0.026 \\
\hline
\end{tabular}

adjusted for age and gender distributions according to the age, sex and educational level, bany suicidal thoughts and behaviors: either suicidal ideation, suicidal plan or suicide attempt

Table 2. Location of suicidal thoughts and behaviors at onset

\begin{tabular}{|c|c|c|c|c|}
\hline \multirow{2}{*}{ Categories } & \multicolumn{3}{|c|}{ Location } & \multirow{2}{*}{ Total, N (\%) } \\
\hline & North Korea, N (\%) & Third country, N (\%) & South Korea, N (\%) & \\
\hline Suicidal ideation & $28(9.3)$ & $53(17.7)$ & $4(1.3)$ & $85(28.3)$ \\
\hline Suicidal plan & $12(4.0)$ & $27(9.0)$ & $1(0.3)$ & $40(13.3)$ \\
\hline Suicide attempt & $16(5.3)$ & $35(11.7)$ & $1(0.3)$ & $52(17.3)$ \\
\hline
\end{tabular}

al thoughts and behaviors (AOR=2.1, 95\% CI=1.1-4.1). Presence of health problems over the past year also was strongly associated with suicidal ideation ( $\mathrm{AOR}=2.6,95 \% \mathrm{CI}=1.4-4.6)$, attempts ( $\mathrm{AOR}=2.6,95 \% \mathrm{CI}=1.2-5.4)$ and any suicidal thoughts and behaviors $(\mathrm{AOR}=2.6,95 \% \mathrm{CI}=1.5-4.7)$.

Responders with military experience had lower odds of suicidal ideation $(\mathrm{AOR}=0.3,95 \% \mathrm{CI}=0.1-0.7)$ and any lifetime suicidal thoughts and behaviors $(\mathrm{AOR}=0.3,95 \% \mathrm{CI}=$ $0.1-0.7)$ with statistical significance $(\mathrm{p}<0.01)$. Suicidal ideation was also associated with absence of South Korean friends or family living in South Korea (AOR=1.9, 95\% CI=1.0-3.4), and absence contact with North Korean family (AOR=1.7, 95\% $\mathrm{CI}=1.0-2.9)$.

\section{The association between specific psychiatric disorders and each suicidal thought and behaviors}

Presence of a mental disorder was associated with significantly increased risk for suicide ideation, plan, and attempt, after controlling for sociodemographic factors including age, gender, education years affecting suicidal thoughts and behaviors (Table 4). Of all measured mental disorder categories, participants with lifetime agoraphobia had the highest odds of suicidal ideation $(\mathrm{AOR}=6.5,95 \% \mathrm{CI}=2.0-21.6)$, plans $(\mathrm{AOR}=7.7,95 \% \mathrm{CI}=2.5-23.2)$ and attempts $(\mathrm{AOR}=12.0,95 \%$ $\mathrm{CI}=3.5-40.8$ ). Reporting lifetime PTSD, social phobia, specific phobia, major depressive disorder and alcohol dependence were associated with twice as high odds of suicidal thoughts and behaviors $(\mathrm{p}<0.05)$.

\section{DISCUSSION}

This study is the first to investigate suicidal thoughts and behaviors among North Korean defectors by sociodemographic characteristics and psychiatric diagnosis. In particular, this study is meaningful for the relatively homogeneous group of defectors who recently arrived in South Korea, with an average resettlement period of $1.4( \pm 2.4)$ years.

The North Korean defectors showed higher lifetime prevalence of suicidal thoughts and behaviors compared to South Koreans. The nationwide sample of South Koreans in 2016 showed that the lifetime prevalence of suicidal ideation, plans, attempts were $15.4,3.0$, and $2.4 \%$, respectively, ${ }^{15}$ The rates of suicidal thoughts and behaviors among North Korean refugees in this study are the highest $(31.3 \%)$ compared to nation-wide prevalence in Western countries and Asian countries ranging from $0.9 \%$ to $15.9 \%{ }^{16,17}$ This is also high when compared with other large scale refugee research on suicidal thoughts and behaviors; $27.3 \%$ (Nigeria) ${ }^{8}$ and 21.5\% (Bhu$\tan ) .^{7}$ Especially, the prevalence of suicidal thoughts and behaviors among those who passed through third transit countries was particularly high. Several studies of refugees in other countries and North Korean defectors have also shown higher rates of mental illness in transit countries. ${ }^{2,18,19}$ Defects may be more vulnerable to mental disorders in transit countries due to human trafficking experience, monitoring of Chinese police, fear of repatriation, difficulties in China living (such as cultural differences, forced marriage, etc.), inappropriate treatment because of the lack of visa or protection. ${ }^{2,3,19}$

North Korean female defectors also showed a high rate of lifetime suicidal thoughts and behaviors, and age did not show a clear tendency. Although some of recent papers have reported that suicidal thought or poor sociocultural adaptation are more prevalent in North Korean female defectors with sexual violence, ${ }^{20,21}$ we did not find such information in this study.

Lifetime psychiatric disorder increased the suicidal thoughts and behaviors in consistent manner with previous literature. Especially, several studies have revealed that anxiety disorder was found to be an independent risk factor for suicide. ${ }^{22,23}$ Ref- 
Table 3. Adjusted odds ratios of each lifetime suicidal thoughts and behaviors for demographic variables ${ }^{a}$

\begin{tabular}{|c|c|c|c|c|}
\hline \multirow[t]{2}{*}{ Variables } & $\begin{array}{l}\text { Suicidal ideation } \\
\qquad(\mathrm{N}=85)\end{array}$ & $\begin{array}{l}\text { Suicidal plan } \\
\qquad(\mathrm{N}=40)\end{array}$ & $\begin{array}{l}\text { Suicide attempt } \\
\qquad(\mathrm{N}=52)\end{array}$ & $\begin{array}{l}\text { Any suicidal thoughts and } \\
\text { behaviors }(\mathrm{N}=94)\end{array}$ \\
\hline & AOR $(95 \% \mathrm{CI})$ & $\mathrm{AOR}(95 \% \mathrm{CI})$ & $\operatorname{AOR}(95 \% \mathrm{CI})$ & $\mathrm{AOR}(95 \% \mathrm{CI})$ \\
\hline \multicolumn{5}{|l|}{ Gender } \\
\hline Female $(\mathrm{N}=235)$ & $2.0(1.0-3.9)^{*}$ & $1.6(0.7-4.2)$ & $1.6(0.7-3.7)$ & $2.1(1.1-4.1)^{*}$ \\
\hline Male $(\mathrm{N}=65)$ & 1 & 1 & 1 & 1 \\
\hline \multicolumn{5}{|l|}{ Age } \\
\hline $18-29(\mathrm{~N}=84)$ & $1.5(0.3-7.5)$ & $0.6(0.1-3.1)$ & $1.5(0.2-13.3)$ & $1.8(0.3-8.9)$ \\
\hline $30-39(\mathrm{~N}=76)$ & $1.7(0.3-7.5)$ & $0.5(0.1-2.9)$ & $3.1(0.4-26.5)$ & $1.7(0.3-8.7)$ \\
\hline $40-49(\mathrm{~N}=80)$ & $1.5(0.3-7.5)$ & $0.5(0.1-2.9)$ & $1.8(0.2-15.4)$ & $1.7(0.3-8.7)$ \\
\hline $50-59(\mathrm{~N}=49)$ & $1.7(0.3-9.2)$ & $0.6(0.1-3.6)$ & $1.7(0.2-15.7)$ & $2.0(0.4-10.8)$ \\
\hline$>60(\mathrm{~N}=11)$ & 1 & 1 & 1 & 1 \\
\hline \multicolumn{5}{|l|}{ Marital status } \\
\hline Married (N=99) & 1 & 1 & 1 & 1 \\
\hline Div/Sep/Wid ${ }^{c}(\mathrm{~N}=87)$ & $1.3(0.7-2.5)$ & $1.4(0.6-3.4)$ & $1.6(0.8-3.6)$ & $1.3(0.7-2.4)$ \\
\hline Unmarried $(\mathrm{N}=114)$ & $1.0(0.5-1.9)$ & $1.3(0.6-3.1)$ & $1.3(0.6-2.8)$ & $1.1(0.6-2.1)$ \\
\hline \multicolumn{5}{|l|}{ Occupational status } \\
\hline Yes $(\mathrm{N}=86)$ & 1 & 1 & 1 & 1 \\
\hline No $(\mathrm{N}=45)$ & $0.9(0.4-2.0)$ & $1.9(0.9-3.5)$ & $1.5(0.6-4.0)$ & $0.9(0.4-1.9)$ \\
\hline \multicolumn{5}{|l|}{ Years of education } \\
\hline$\leq 9(\mathrm{~N}=58)$ & $1.2(0.5-2.6)$ & $1.3(0.5-3.6)$ & $1.9(0.7-4.9)$ & $1.0(0.4-2.1)$ \\
\hline 10-11 (high school) $(\mathrm{N}=166)$ & $1.1(0.6-1.8)$ & $1.0(0.4-2.1)$ & $1.4(0.6-3.0)$ & $0.9(0.5-1.7)$ \\
\hline$\geq 12$ (college) $(\mathrm{N}=76)$ & 1 & 1 & 1 & 1 \\
\hline \multicolumn{5}{|l|}{ Economics status } \\
\hline$<\$ 1000(\mathrm{~N}=191)$ & $1.1(0.6-1.8)$ & $2.4(1.0-5.3)^{*}$ & $1.4(0.7-2.7)$ & $1.1(0.7-2.0)$ \\
\hline$\geq \$ 1000(\mathrm{~N}=102)$ & 1 & 1 & 1 & 1 \\
\hline \multicolumn{5}{|l|}{ Forced repatriation experience } \\
\hline Yes $(\mathrm{N}=40)$ & $1.0(0.5-2.1)$ & $1.5(0.6-3.7)$ & $1.4(0.6-3.3)$ & $0.8(0.4-1.8)$ \\
\hline No $(N=260)$ & 1 & 1 & 1 & 1 \\
\hline \multicolumn{5}{|l|}{ Military service experience } \\
\hline Yes $(\mathrm{N}=49)$ & $0.3(0.1-0.7)^{\dagger}$ & $0.2(0.1-1.0)$ & $0.4(0.1-1.1)$ & $0.3(0.1-0.7)^{\dagger}$ \\
\hline No $(N=251)$ & 1 & 1 & 1 & 1 \\
\hline \multicolumn{5}{|l|}{ Political party affiliation } \\
\hline Yes $(\mathrm{N}=36)$ & $0.8(0.3-2.1)$ & $0.7(0.2-2.7)$ & $1.1(0.3-3.4)$ & $0.9(0.3-2.2)$ \\
\hline No $(N=264)$ & 1 & 1 & 1 & 1 \\
\hline \multicolumn{5}{|c|}{ South Korean friends or family living in South Korea } \\
\hline Yes $(N=225)$ & 1 & 1 & 1 & 1 \\
\hline No $(\mathrm{N}=75)$ & $1.9(1.0-3.4)^{*}$ & $1.5(0.7-3.2)$ & $1.5(0.8-3.1)$ & $1.8(1.0-3.3)^{*}$ \\
\hline \multicolumn{5}{|c|}{ North Korean family presence in contact } \\
\hline Yes $(N=137)$ & 1 & 1 & 1 & 1 \\
\hline No $(N=160)$ & $1.7(1.0-2.9)^{*}$ & $1.7(0.9-3.4)$ & $1.4(0.8-2.6)$ & $1.6(0.9-2.6)$ \\
\hline \multicolumn{5}{|l|}{ Health problems over the past year } \\
\hline Yes $(\mathrm{N}=194)$ & $2.6(1.4-4.6)^{\dagger}$ & $1.5(0.7-3.1)$ & $2.6(1.2-5.4)^{\dagger}$ & $2.6(1.5-4.7)^{\dagger}$ \\
\hline No $(\mathrm{N}=106)$ & 1 & 1 & 1 & 1 \\
\hline
\end{tabular}

adjusted for age and gender distributions according to the age, sex and educational level, bany suicidal thoughts and behaviors: either suicidal ideation, suicidal plan or suicide attempt, ${ }^{c}$ Divorced/Separated/Widowed. ${ }^{*} \mathrm{p}<0.05,{ }^{\dagger} \mathrm{p}<0.01,{ }^{\ddagger} \mathrm{p}<0.001$ 
Table 4. Adjusted Odds Ratios of DSM-IV/CIDI mental disorders among responders with versus without each suicidal thoughts and behaviors $^{\mathrm{a}}$

\begin{tabular}{|c|c|c|c|c|c|c|c|c|}
\hline \multirow{2}{*}{ Disorders } & \multicolumn{2}{|c|}{ Suicidal ideation $(\mathrm{N}=85)$} & \multicolumn{2}{|c|}{ Suicidal plan $(\mathrm{N}=40)$} & \multicolumn{2}{|c|}{ Suicide attempt $(\mathrm{N}=52)$} & \multicolumn{2}{|c|}{$\begin{array}{l}\text { Any suicidal thoughts and } \\
\text { behaviors }^{\mathrm{b}}(\mathrm{N}=94)\end{array}$} \\
\hline & AOR $(95 \% \mathrm{CI})$ & $\mathrm{N}(\%)$ & $\operatorname{AOR}(95 \% \mathrm{CI})$ & $\mathrm{N}(\%)$ & $\operatorname{AOR}(95 \% \mathrm{CI})$ & $\mathrm{N}(\%)$ & $\operatorname{AOR}(95 \% \mathrm{CI})$ & $\mathrm{N}(\%)$ \\
\hline Anxiety disorder & $1.5(1.3-1.7)^{\ddagger}$ & $57(67.1)$ & $1.5(1.2-1.8)^{\ddagger}$ & $29(34.1)$ & $1.6(1.4-1.9)^{\ddagger}$ & $40(47.1)$ & $1.5(1.3-1.7)^{\ddagger}$ & $62(72.9)$ \\
\hline GAD & $1.9(0.8-3.9)$ & $15(17.6)$ & $1.0(0.4-2.8)$ & $5(5.9)$ & $1.6(0.7-3.7)$ & $9(10.6)$ & $2.4(1.2-4.8)^{*}$ & $18(21.2)$ \\
\hline Panic disorder & $2.0(1.0-3.9)^{*}$ & $7(8.2)$ & $2.3(0.7-7.5)$ & $4(4.7)$ & $2.9(1.0-8.4)^{*}$ & $6(7.1)$ & $2.7(1.0-7.6)^{*}$ & $9(10.6)$ \\
\hline Agoraphobia & $6.5(2.0-21.6)^{\dagger}$ & $10(11.8)$ & $7.7(2.5-23.2)^{\ddagger}$ & $7(8.2)$ & $12.0(3.5-40.8)^{\ddagger}$ & $9(10.6)$ & $8.3(2.2-30.7)^{\dagger}$ & $11(12.9)$ \\
\hline PTSD & $3.5(1.8-6.6)^{\ddagger}$ & $24(28.2)$ & $3.3(1.6-7.1)^{\dagger}$ & $13(15.3)$ & $3.5(1.8-7.1)^{\ddagger}$ & $17(20.0)$ & $2.6(1.4-5.0)^{\dagger}$ & $24(28.2)$ \\
\hline Social phobia & $3.9(1.6-9.5)^{\dagger}$ & $13(15.3)$ & $3.5(1.3-9.1)^{*}$ & $7(8.2)$ & $5.9(2.4-14.9)^{\ddagger}$ & $11(12.9)$ & $4.0(1.6-10.1)^{\dagger}$ & $14(16.5)$ \\
\hline Specific phobia & $4.9(2.8-8.8)^{\ddagger}$ & $17(20.0)$ & $3.6(1.8-7.3)^{\ddagger}$ & $18(21.2)$ & $4.3(2.2-8.1)^{\ddagger}$ & $24(28.2)$ & $4.9(2.7-8.7)^{\ddagger}$ & $40(47.1)$ \\
\hline Mood disorder & $1.4(1.2-1.6)^{\ddagger}$ & $39(45.9)$ & $1.2(1.0-1.5)^{*}$ & $17(20.0)$ & $1.2(1.1-1.5)^{\dagger}$ & $22(25.9)$ & $1.4(1.2-1.6)^{\ddagger}$ & $42(49.4)$ \\
\hline MDD & $4.0(2.3-7.1)^{\ddagger}$ & $38(44.7)$ & $2.4(1.2-4.8)^{*}$ & $16(18.8)$ & $2.5(1.3-4.8)^{\dagger}$ & $21(24.7)$ & $3.7(2.1-6.5)^{\ddagger}$ & $40(47.1)$ \\
\hline Dysthymia & $2.3(0.8-6.1)$ & $8(9.4)$ & $4.0(1.4-11.5)^{*}$ & $6(7.1)$ & $2.6(0.9-7.4)$ & $6(7.1)$ & $2.5(0.9-6.7)$ & $9(10.6)$ \\
\hline Alcohol use disorder & $1.3(1.1-1.6)^{\dagger}$ & $20(23.5)$ & $1.1(0.9-1.4)$ & $9(10.6)$ & $1.4(1.1-1.7)^{\dagger}$ & $15(17.6)$ & $1.3(1.1-1.6)^{\dagger}$ & $22(25.9)$ \\
\hline Alcohol dependence & $4.5(2.0-10.0)^{\ddagger}$ & $17(20.0)$ & $2.5(1.0-5.9)^{*}$ & $8(9.4)$ & $4.4(1.9-10.5)^{\dagger}$ & $12(14.1)$ & $4.4(2.0-10.0)^{\ddagger}$ & $18(21.2)$ \\
\hline Alcohol abuse & $2.0(0.9-4.5)$ & $12(14.1)$ & $1.4(0.5-4.1)$ & $5(5.9)$ & $2.5(1.0-6.1)^{*}$ & $9(10.6)$ & $2.4(1.1-5.3)^{*}$ & $14(16.5)$ \\
\hline Nicotine use disorder & $1.2(0.9-1.6)$ & $19(22.4)$ & $1.3(0.9-1.8)$ & $4(4.7)$ & $1.1(0.8-1.5)$ & $4(4.7)$ & $1.2(0.9-1.6)$ & $8(9.4)$ \\
\hline Any DSM-IV disorders & $5.1(2.8-9.4)^{\ddagger}$ & $68(80.0)$ & $3.6(1.6-8.1)^{\dagger}$ & $32(37.6)$ & $5.8(2.6-13.0)^{\ddagger}$ & $44(51.8)$ & $5.0(2.8-8.9)^{\ddagger}$ & $74(87.6)$ \\
\hline
\end{tabular}

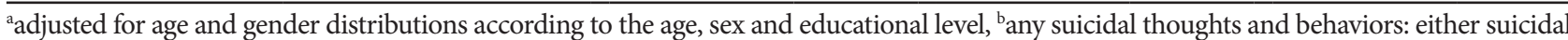
ideation, suicidal plan or suicide attempt. ${ }^{*} \mathrm{p}<0.05,{ }^{\dagger} \mathrm{p}<0.01,{ }^{\ddagger} \mathrm{p}<0.001$. GAD: generalized anxiety disorder, PTSD: post-traumatic disorder, MDD: major depressive disorder, DSM-IV: diagnostic statistical manual of mental disorders, fourth edition, CI: confidence interval, AOR: adjusted odds ratios

ugee suicides studies have also reported association between high level of anxiety and suicidal ideation. ${ }^{\text {? }}$

In this study, agoraphobia was the most strongly associated with suicidal ideation, plan, and attempt. Other anxiety disorders such as PTSD, social phobia, and specific phobia also showed a significant association with suicidal thoughts and behaviors. This should be distinguished from the recent refugee suicide literatures that have mainly focused on PTSD.

Previous studies have reported inconsistent results concerning agoraphobia. One study showed that agoraphobia without panic disorder was also associated with suicidal thoughts and behaviors, ${ }^{23}$ but other reported no associacition. ${ }^{24}$ Study with the Korean Epidemiologic Catchment Area study Replication (KECA-R, between August 2006 and April 2007) showed that anxiety disorder other than panic disorder and agoraphobia was associated with suicidal ideation and plan, which was based on nationally-representative sample of 6,510 South Korean adults aged 18-64 years. ${ }^{25}$

One possible explanation is that it is difficult to differentiate the diagnoses between PTSD and specific phobia among North Korean defectors, where an individual might have experienced multiple fearful situations within the agoraphobia clusters, including being trapped in an enclosed space or being forced to leave home. Another hypothesis is that individual fears or avoidance with the thought that escape might be difficult or help might not be available may related to danger of censorship, search, and detection which are special in defection process. In addition, North Korean defectors tend to experience different form of traumatic events such as food shortages, unwanted breakups with their families, and forced repatriation with more consistent and repetitive pattern, ${ }^{26}$ while other war refugee experiencing war, death, execution, and torture directly reported prevalent full- diagnostic PTSD. ${ }^{27-29}$ This suggests that chronic subthreshold anxiety symptoms from predefection to after settlement might be more prevalent in study participants and associated to suicidal thoughts and behaviors. Further research and replication will be necessary on the casual relation between the onset of various types of anxiety disorders and suicidal thoughts and behaviors among defectors.

We also investigated various additional personal experiences related to North Korean defectors such as forced repatriation, military service, political party affiliation with suicidal thoughts and behaviors.

It is noteworthy that the experience of military service appeared to reduce the risk for suicide ideation and any suicidal thoughts and behaviors. Referring to the previous literature, suicide mortality rate among conscripts has been lower than suicide rate among young men who do not serve in the military in Finland. ${ }^{30}$ The studies with U.S. Army had also hypothesized that the historically lower rate among military service 
members were the screening out of those with significant mental health problems or a documented criminal history, the availability of a strong social network, and ready access to health care ${ }^{31}$ However, beginning in 2008 the rate of suicide among soldiers in the U.S. Army as exceeded that of the adjusted general population for the first time in decades, ${ }^{32}$ with the explanation in part that the recent increase in suicides parallels an increase in the prevalence of mental disorders across the army. ${ }^{33} \mathrm{~A}$ follow-up study of defector suicides with military experience will be necessary depending on the change in prevalence of mental disorder compared with ordinary citizens from this perspective.

It is thought that the inner, subjective experience of social connectedness is an important suicide preventing factor because the risk of suicide ideation is increased when there is no Korean acquaintance or contacted North Korean family. Interpersonal theory of suicide hypotheses that thwarted belongingness and perceived burdensome construct of suicidal desire, ${ }^{34}$ supported by several studies reporting significant association between social connection and suicide ideation. ${ }^{35,36}$ Social connectedness might also be related to suicidal ideation in the process of refugee settlement. ${ }^{37}$ Worries about family back in North Korea, linguistic differences and cultural discrimination may contribute to such result. In other refugee studies, being separated from family and poor heath were also cited as major causes. ${ }^{7}$

One of the limitations in this study is that the sample size is small and there may be recall bias associated with lifetime suicidal thoughts and behaviors and psychiatric diagnosis due to the nature of a retrospective study. Also, North Korean defectors early in their resettlement period might have a low understanding of diagnostic questionnaire due to the variations in their North Korean dialect. The mental health conditions of defectors living in Hana Center and the defectors living in the community may differ depending on the time of arrival and the quality of the living.

As shown in this study, the suicidal thoughts and behaviors rate of the North Korean defector is high. Since the number of North Korean defectors is continuously increasing, basic data on their mental health status during and after the entrance of South Korea are needed to provide psychiatric support tools as part of their resettlement process. Our follow-up study and psychiatric intervention should focus on changes in suicidal thoughts and behaviors of defectors according to the process and time of escape and the prevalence of the psychiatric problems during their resettlement process.

In conclusion, the prevalence of suicidal thoughts and behaviors among North Korean refugees is much higher than the general population in South Korea, and they are especially high among those who passed through transit countries.
Female sex, presence of health problems over the past year and absence of social connectedness were strongly associated with suicidal ideation. Agoraphobia was the most influential factor for suicidal thoughts and behaviors on adjusting for socio-demographic variables. Further research should focus on tracking suicidal thoughts and behaviors in each process of defection and finding risk factors for early prevention.

\section{Acknowledgments}

This work was supported by the Korea Healthcare Technology R\&D project, Ministry of Health and Welfare, Republic of Korea (HM15C1072).

\section{REFERENCES}

1. Ministry of Unification. Number of North Korean refugees entered the south. Available at: https://www.unikorea.go.kr/content.do? cmsid=1440. Accessed May 21, 2017.

2. Lee Y, Lee MK, Chun KH, Lee YK, Yoon SJ. Trauma experience of North Korean refugees in China. Am J Prev Med 2001;20:225-229.

3. Jung YJ, Choi BN. Effects of the length of stay in transit country and forcible repatriation experience on the mental health of North Korean refugee women resettled in South Korea: BPSI-NKR Analysis. Korean J Psychol 2017;22:47-67.

4. Park S, Lee M, Jeon JY. Factors affecting depressive symptoms among North Korean adolescent refugees residing in South Korea. Int J Environ Res Public Health 2017;14:912.doi:10.3390/ijerph14080912.

5. Choi Y, Lim SY, Jun JY, Lee SH, Yoo SY, Kim S, et al. The effect of traumatic experiences and psychiatric symptoms on the life satisfaction of North Korean refugees. Psychopathology 2017;50:203-210.

6. Kim HH, Lee YJ, Kim HK, Kim JE, Kim SJ, Bae SM, et al. Prevalence and correlates of psychiatric symptoms in North Korean defectors. Psychiatry Investig 2011;8:179-185.

7. Lustig SL, Kia-Keating M, Knight WG, Geltman P, Ellis H, Kinzie JD, Saxe GN. Review of child and adolescent refugee mental health. J Am Acad Child Adolesc Psychiatry 2014;43:24-36.

8. Akinyemi OO, Atilola O, Soyannwo T. Suicidal ideation: are refugees more at risk compared to host population? Findings from a preliminary assessment in a refugee community in Nigeria. Asian J Psychiatr 2015; 18: 81-85.

9. Falb KL, McCormick MC, Hemenway D, Anfinson K, Silverman JG. Suicide ideation and victimization among refugee women along the Thai-Burma border. J Trauma Stress 2013;26:631-635.

10. Cochran J, Geltman PL, Ellis H, Brown C, Anderton S, Montour J, et al. Suicide and Suicidal Ideation Among Bhutanese Refugees - United States, 2009-2012. MMWR Morbid Mortal W 2013;62:533-536.

11. Shin HY, Lee H, Park SM. Mental health and its associated factors among North Korean defectors living in South Korea. Asia Pac J Public Health 2016;28:592-600.

12. Kessler RC, Ustun TB. The World Mental Health (WMH) Survey Initiative Version of the World Health Organization (WHO) Composite International Diagnostic Interview (CIDI). Int J Methods Psychiatr Res 2004;13:93-121.

13. Lee T, Ahn MH, Jun JY, Han JM, Lee SH, Hahm BJ, et al. Development of North Korean version of the composite international diagnostic interview. J Korean Neuropsychiatr Assoc 2015;54:228-235.

14. Statistics Korea, 2016. Available at: https://kosis.kr. Accessed May 21, 2017.

15. Schroderus M, Lönnqvist JK, Aro HM. Trends in suicide rates among military conscripts. Acta Psychiatr Scand 1992;86:233-235.

16. Nock MK, Borges G, Bromet EJ, Alonso J, Angermeyer M, Beautrais A, et al. Cross-national prevalence and risk factors for suicidal ideation, plans and attempts. Br J Psychiatry 2008;192:98-105.

17. Varnik P. Suicide in the world. Int J Environ Res Public Health 2012;9: 
760-771.

18. Robjant K, Hassan R, Katona C. Mental health implications of detaining asylum seekers: systematic review. Br J Psychiatry 2009;194:306-312.

19. Yu SE, Jeon WT. Mental health of north korean refugees in protective facilities in china. Psychiatry Investig 2008;5:70-77.

20. Kim JY, Kim HJ, Choi K, Nam B. Mental health conditions among North Korean female refugee victims of sexual violence. Int Migr 2017;55:6879.

21. Um MY, Kim HJ, Palinkas LA. Correlates of domestic violence victimization among North Korean refugee women in South Korea. J Interpers Viol 2016 [Epub ahead of print]

22. Bolton JM, Cox BJ, Afifi TO, Enns MW, Bienvenu OJ, Sareen J. Anxiety disorders and risk for suicide attempts: findings from the Baltimore Epidemiologic Catchment area follow-up study. Depress Anxiety 2008;25: 477-481.

23. Sareen J, Cox BJ, Afifi TO, de Graaf R, Asmundson GJ, ten Have M, et al. Anxiety disorders and risk for suicidal ideation and suicide attempts: a population-based longitudinal study of adults. Arch Gen Psychiatry 2005;62:1249-1257.

24. Huang MF, Yen CF, Lung FW. Moderators and mediators among panic, agoraphobia symptoms, and suicidal ideation in patients with panic disorder. Compr Psychiatry 2010;51:243-249.

25. Cho SJ, Hong JP, Lee JY, Im JS, Na KS, Park JE, et al. association between DSM-IV anxiety disorders and suicidal behaviors in a community sample of South Korean adults. Psychiatry Investig 2016;13:595-600.

26. Kim YH, Jeon WT, Cho YA. A study on the prevalence and the influencing factors of the mental health problems among recent migrant North Koreans: a focus on 2007 entrants. Unific Policy Stud 2010;19:141174.

27. Tufan AE, Alkin M, Bosgelmez S. Post-traumatic stress disorder among asylum seekers and refugees in Istanbul may be predicted by torture and loss due to violence. Nord J Psychiatry 2013;67:219-224.

28. Badri A, Crutzen R, Van den Borne HW. Exposures to war-related traumatic events and post-traumatic stress disorder symptoms among displaced Darfuri female university students: an exploratory study. BMC Public Health 2012;12:603.

29. Silove D, Steel Z, McGorry P, Miles V, Drobny J. The impact of torture on post-traumatic stress symptoms in war-affected Tamil refugees and immigrants. Compr Psychiatry 2002;43:49-55.

30. Schroderus M, Lonnqvist JK, Aro HM. Trends in Suicide Rates among Military Conscripts. Acta Psychiatr Scand 1992;86:233-235.

31. Nock MK, Deming CA, Fullerton CS, Gilman SE, Goldenberg M, Kessler RC, et al. Suicide among soldiers: a review of psychosocial risk and protective factors. Psychiatry 2013;76:97-125.

32. Kuehn BM. Soldier suicide rates continue to rise: military, scientists work to stem the tide. JAMA 2009;301:1111, 1113.

33. Bachynski KE, Canham-Chervak M, Black SA, Dada EO, Millikan AM, Jones BH. Mental health risk factors for suicides in the US Army, 2007-8. Inj Prev 2012;18:405-412.

34. Van Orden KA, Witte TK, Cukrowicz KC, Braithwaite SR, Selby EA, Joiner TE Jr. The interpersonal theory of suicide. Psychol Rev 2010;117: 575-600.

35. Timmons KA, Selby EA, Lewinsohn PM, Joiner TE. Parental displacement and adolescent suicidality: exploring the role of failed belonging. J Clin Child Adolesc Psychol 2011;40:807-817.

36. Arango A, Opperman KJ, Gipson PY, King CA. Suicidal ideation and suicide attempts among youth who report bully victimization, bully perpetration and/or low social connectedness. J Adolesc 2016;51:19-29.

37. Ellis BH, Lankau EW, Ao T, Benson MA, Miller AB, Shetty S, et al. Understanding Bhutanese Refugee Suicide Through the InterpersonalPsychological Theory of Suicidal Behavior. Am J Orthopsychiatry 2015; 85:43-55. 